\title{
HIPPARCHUS'S COMPUTATIONS OF SOLAR LONGITUDES
}

\author{
ALEXANDER JONES, University of Toronto
}

The treatment of solar theory in Book III of the Almagest is the cornerstone of Ptolemy's deduction of the models of the celestial motions. While his analysis of the motions of the other planets - and even the fixed stars - presupposes the possibility of computing solar positions, the solar theory can, and indeed must, be worked out fully from solstice and equinox observations without reference to any other heavenly body. Ptolemy draws our attention to the dependence of the rest of his astronomy on the solar theory, and points out that it determines the logical order of topics that his treatise must follow.' Now by his own admission all the parameters of Ptolemy's simple eccentric model for the Sun exactly reproduced parameters proposed by Hipparchus three hundred years earlier. So did the whole of Hipparchus's solar theory correspond in all major respects to Ptolemy's, and hold a similar position as the stepping-stone to Hipparchus's other astronomical researches? Since none of Hipparchus's writings relating to the solar and lunar theory survives, the answer must be sought in the fragmentary reports of his works given by later authors, and above all by Ptolemy himself.

Ptolemy proceeds through the solar theory in the following stages. First (in Almagest III, 1) he determines the length of the tropical year by a comparison of solstice and equinox observations over long intervals, and shows that the tropical year is constant; treating this interval by convention as the period of one revolution of the Sun about the ecliptic, he sets out a table of mean solar motion in longitude as a function of time (III, 2). Thereupon, he describes the kind of model (a simple eccentre) that is appropriate for describing the Sun's anomaly (III, 3-4), and determines longitude of the apsidal line and the ratio of eccentricity by a trigonometric analysis of the observed lengths of the astronomical seasons in his time. These parameters, Ptolemy points out, are manifestly constant, since Hipparchus found just the same season lengths three centuries earlier. On the basis of this now quantified model (see Figure 1), Ptolemy constructs a table of the Sun's equation of centre as a function of its mean elongation from the apogee (III, 5-6). The last requirement to complete the tables (III, 7) is the determination of the Sun's mean longitude at an epoch date. After giving instructions for use of the tables (III, 8), Ptolemy closes the discussion of solar theory with an analysis and rules for computing the equation of time, that is, the correction of time intervals between observations to account for the difference between mean and true solar days (III, 9).

Some of these steps had a clearly attested counterpart in Hipparchus's work, although they were distributed among several different monographs. In treatises entitled "On the length of the year" and "On intercalary months and days" Hipparchus proposed a value for the length of the tropical year of $365 \frac{1}{4}-\frac{1}{300}$ days, 


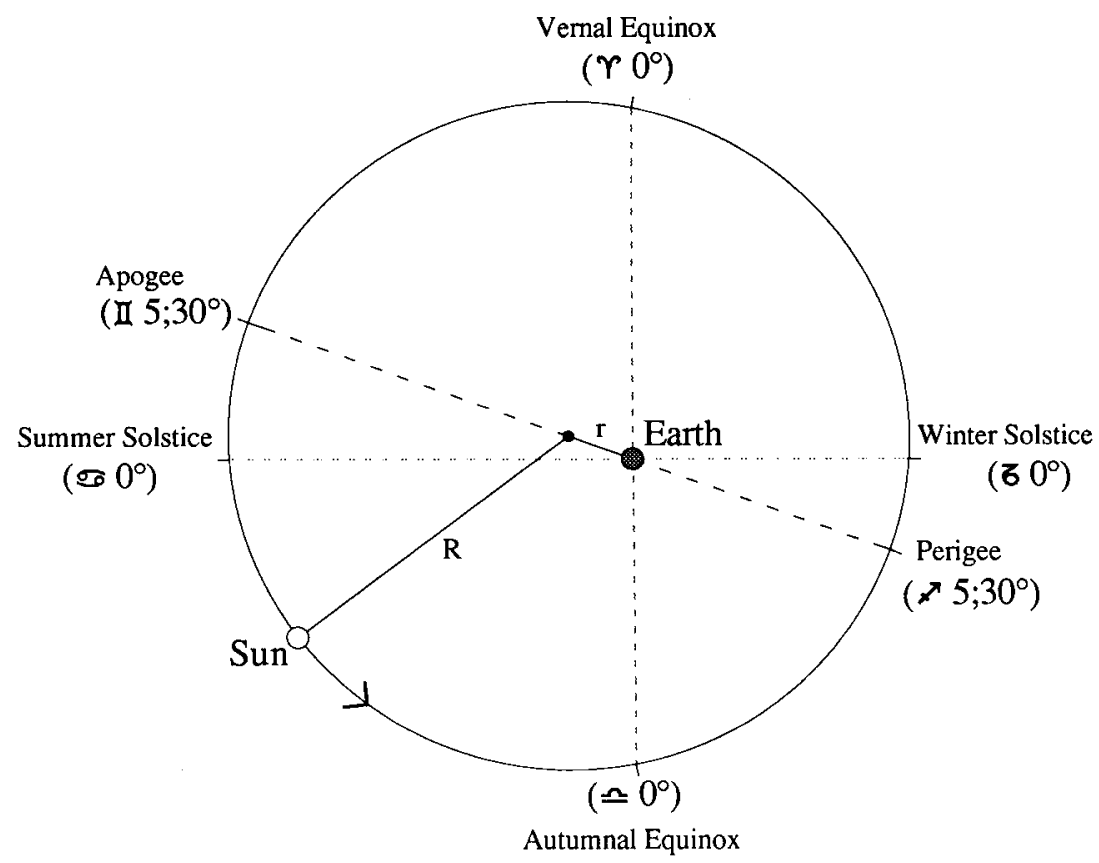

Fig. 1. Ptolemy's and Hipparchus's solar model $(r: R=1: 24)$.

which is exactly the value that Ptolemy adopts. ${ }^{2}$ In another treatise of uncertain title, ${ }^{3}$ Hipparchus assumed either a simple eccentre model like Ptolemy's, or the geometrically equivalent simple epicyclic model, and determined its ratio of eccentricity (approximately $1: 24)$ and the longitude of the apogee $\left(24 \frac{1}{2}^{\circ}\right.$ before the summer solstice) from the observed intervals of $94 \frac{1}{2}$ days between vernal equinox and summer solstice and $92 \frac{1}{2}$ days between summer solstice and autumnal equinox: again these will be Ptolemy's parameters. ${ }^{4}$ Hipparchus was thus in possession of all the ingredients of a solar theory exactly corresponding in every particular to Ptolemy's. Did he, therefore, produce equivalent tables based on this theory? Most historians who have dealt with Hipparchus's solar theory have assumed so. ${ }^{5}$ Yet the positive evidence for such tables consists of no more than a single allusion by the astrologer Vettius Valens (c. A.D. 170) to solar tables "of Hipparchus". ${ }^{6}$ From this source we learn that Hipparchus's tables were supposed to be as accurate as any known to Valens, and that they set the vernal equinox at Aries $0^{\circ}$ (as one would expect for Hipparchus, but contrasting with the Babylonian norms preferred by Valens).

Even if Vettius Valens had told us more about these solar tables, we would not be justified in presuming that practical astronomical tables circulating under Hipparchus's name in the second century of our era had come down from Hipparchus's pen without considerable adaptation. Nor are we entirely safe in assuming that any tables that Hipparchus did publish were based on the precise model and parameters that Ptolemy adopts. It is clear from Ptolemy's discus- 
sion in Almagest III, 1 that Hipparchus's value of $365 \frac{1}{4}-\frac{1}{300}$ days for the length of the tropical year was a result hard won after much uncertainty about whether the tropical year was even of constant length; and the work "On the displacement of the solsticial and equinoctial points", in which Hipparchus raised these doubts in connection with his discovery of the precession of the equinoxes, was written in or after -127 , late in Hipparchus's career. ${ }^{7}$ Moreover, Hipparchus was able to determine the eccentricity and apsidal line of the solar model only for his own time, so that he had no firm grounds for assuming that the apsidal line was tropically fixed. That he did so assume "in his theories of the Sun and Moon" we must accept from Ptolemy's statement; ${ }^{8}$ but it is also obvious that Ptolemy is at pains to emphasise the points of agreement between his own results and Hipparchus's, a motive that might have led him to gloss over embarrassing inconsistencies in Hipparchus's opinions. And besides, granted that at some stage of his life Hipparchus was working from the same model as Ptolemy, he need not have expressed its behaviour in tables of the same structure: a wide variety of formats was possible, as Ptolemy himself points out, ${ }^{9}$ and the numerical representation of the solar anomaly, instead of being computed for a whole range of tabular entries by the correct trigonometric analysis of the model, might be a simple schematic function 'fitted' to the theoretical parameters of the model.

This much is certain, that Hipparchus did have a method or methods of computing solar longitudes, because Ptolemy reports two or three instances where Hipparchus used calculated solar positions in his works on lunar theory and precession. Thus in his "On the displacement of the solsticial and equinoctial points" Hipparchus compared the tropical longitudes of fixed stars in the early third century and in his own time using observations of lunar eclipses where the Moon was close to or occulted the stars. ${ }^{10}$ Ptolemy describes Hipparchus's method (as applied to his own eclipse observations) as follows:

Likewise, in order to carry out the computations for the above [measurements of the longitude of Spica], he adduces the spring equinoxes which he had accurately observed in those years. This was in order that from the latter he could find the position of the Sun at the middle of each eclipse, from these the positions of the Moon, and from the positions of the Moon those of the stars. ${ }^{11}$

As Ptolemy's account shows, Hipparchus computed the Sun's progress from the equinoctial point during the time elapsed since the observed (or, for his analysis of Timocharis's observations, extrapolated) date of equinox. Unfortunately, Ptolemy does not quote Hipparchus's longitudes; Hipparchus may himself have omitted to report the details of his calculations of the stellar positions, for Ptolemy has only tentative explanations for the source of the errors in them. ${ }^{12}$

Elsewhere (V, 3 and 5), Ptolemy quotes actual figures for solar longitudes from an unidentified work of Hipparchus, but there is some doubt whether these longitudes were predicted or observed. They come from three late observations (dating from -127 and -126 ) in which Hipparchus measured the Moon's elongation from the Sun. ${ }^{13}$ Ptolemy does not tell us what kind of 
instrument Hipparchus used for these observations, and the report could be interpreted as saying either that the Sun was sighted through a diopter preset at a predicted longitude so that the instrument would be aligned with the ecliptic for the lunar sighting, or that the instrument was aligned by some other means, and the Sun's and Moon's longitudes were both observed. ${ }^{14}$

Finally Ptolemy preserves for us two pairs of intervals of solar longitude between lunar eclipses that Hipparchus used for his measurements of the lunar eccentricity or epicycle radius. These are undoubtedly computed, since the eclipses in question occurred long before Hipparchus lived, and the eclipse reports gave only the times, not the longitudes. My chief purpose in this article is to reconstruct the methods by which Hipparchus computed these intervals. The body of data is small - a mere four numbers - and the inferences that I draw from them about Hipparchus's procedures may seem both surprising and unreasonably complicated: for I will argue that Hipparchus computed these intervals of longitude by two slightly different schemes of describing solar motion, and that these schemes, although influenced by the parameters of his solar model, were based in their fundamental structure on the rules for solar motion in the Babylonian System A lunar theory. Such a reconstruction could only be regarded as conjecture so long as there remains the possibility of a simpler explanation of Hipparchus's figures. The first part of my argument will therefore be to prove that the figures cannot be derived from any kind of tables or rules for solar longitude plausible in this period except the kind represented by the Babylonian System A. I will then show what simple modifications of the System A rules are necessary to reproduce Hipparchus's intervals. The last, admittedly speculative, part of the article will suggest reasons for the changes Hipparchus made in the Babylonian scheme, and consider what conclusions may be inferred concerning the purpose and course of Hipparchus's astronomical writings.

\section{The Two Eclipse Trios}

Hipparchus's lunar theory was founded on the hypothesis that the Moon exhibits a single periodic anomaly that can be accounted for either by the Moon's travelling uniformly along an eccentre with a revolving apsidal line, or by supposing the Moon to revolve on an epicycle travelling along a deferent concentric with the Earth. In the eccentric model, the period of revolution of the apsidal line is the anomalistic month, and the Moon revolves about the eccentre once in its sidereal period; in the epicyclic model, the Moon revolves about the epicycle once in an anomalistic month, while the epicycle revolves about the Earth with the sidereal period. Given these equivalences, and that the ratio of the eccentricity to the eccentre's radius in the one model is the same as the ratio of the epicycle radius to the deferent's radius in the other model, the two models will produce geometrically identical lunar orbits, and hence identical apparent positions as seen from the Earth. It is therefore a matter of indifference, from the point of view of mathematical astronomy, which model is assumed in deriving a quantitative lunar theory from observations, and this fact was certainly known to Hipparchus. ${ }^{15}$ 
Nevertheless, as Ptolemy informs us in Almagest IV, 11, Hipparchus made two measurements of the ratio of circles in the lunar model, one according to an eccentric hypothesis, the other according to an epicyclic hypothesis, and the two measurements arrived at significantly different ratios. What is more, neither of these ratios agrees with the ratio that Ptolemy determines in Almagest IV, 6 by a geometrical argument that is, according to Ptolemy, substantially the same as the procedure that Hipparchus followed. ${ }^{16}$ It is Ptolemy's purpose in IV, 11 to demonstrate that the discrepancies were due to inaccuracies in Hipparchus's data, and not to any theoretical inadequacy of the epicyclic or eccentric model.

The ratio of the circles is geometrically determined by three observations of lunar eclipses, where the intervals of time between the eclipses, and the intervals of longitude between the three positions of the Moon - or equivalently of the Sun - are known. The trio of eclipses adduced by Hipparchus for his first measurement using the eccentric hypothesis was observed in $-382 / 381$, and, according to Ptolemy, came from a series of eclipse observations that had been "brought over from Babylon"; the second trio, applied to the epicyclic model, were observed by an unidentified astronomer in Alexandria during $-200 / 199$. Ptolemy reports the following data for the six eclipses, quoting or paraphrasing Hipparchus: ${ }^{17}$

(A1) "The first [of the eclipses observed at Babylon] occurred in the archonship of Phanostratos at Athens, in the month Poseideon; a small section of the Moon's disk was eclipsed from the summer rising point when half an hour of night was remaining ... it was still eclipsed when it set."

(A2) "The next eclipse occurred in the archonship of Phanostratos at Athens, in the month Skirophorion, Phamenoth 24/25 in the Egyptian calendar, and that [the Moon] was eclipsed from the summer rising-point when the first hour [of night] was well advanced ... the duration of the whole eclipse is recorded as three hours ...."

(A3) "The third eclipse occurred in the archonship of Euandros at Athens, in the month Poseideon I, Thoth 16/17 in the Egyptian calendar, and ... [the Moon] was totally eclipsed, beginning from the summer rising-point, after 4 hours [of night] had passed."

(B1) "The first of these [i.e. the eclipses observed at Alexandria] occurred in the 54th year of the Second Kallippic Cycle, Mesore [XII] 16 in the Egyptian calendar. In this eclipse the Moon began to be obscured half an hour before it rose, and its full light was restored in the middle of the third hour [of night]."

(B2) "The next eclipse occurred in the 55th year of the same cycle, Mechir [VI] 9 in the Egyptian calendar ... it began when $5 \frac{1}{3}$ hours of night had passed, and was total."

(B3) "The third eclipse occurred in the same [55th] year of the Second Cycle, on Mesore [XII] 5 in the Egyptian calendar, and ... it began when $6 \frac{2}{3}$ hours of the night had passed, and was total ... mid-eclipse occurred at about $8 \frac{1}{3}$ hours of night, that is, $2 \frac{1}{3}$ seasonal hours after midnight."

For each eclipse Ptolemy adds further data, including the year according to 
TABle 1. Ptolemy's and Hipparchus's intervals.

\begin{tabular}{|c|c|c|c|c|}
\hline \multirow[t]{2}{*}{ Eclipses } & \multicolumn{2}{|c|}{ Ptolemy } & \multicolumn{2}{|c|}{ Hipparchus } \\
\hline & $\Delta \mathrm{t}$ & $\Delta \lambda_{\odot}$ & $\Delta \mathrm{t}$ & $\Delta \lambda_{\odot}$ \\
\hline$A 1-$ & $177^{\mathrm{d}} 13 \frac{7 \mathrm{n} / 2}{\mathrm{n} 18}$ & $173 ; 28^{\circ}$ & $177^{\circ} 13 \frac{3}{4} \mathrm{~h}$ & $173-\frac{1}{8}^{\circ}$ \\
\hline $42-$ & $177^{\mathrm{d}} \quad 2^{\mathrm{h}}$ & $175 ; 44^{\circ}$ & $177^{\mathrm{d}} \quad 1^{\frac{2}{3} \mathrm{~h}}$ & $175 \frac{1}{8}^{\circ}$ \\
\hline $\mathrm{BI}-\mathrm{B} 2$ & $178^{d} \quad 6 \frac{5 h}{6}$ & $180 ; 11^{\circ}$ & $178^{d} 6^{h}$ & $180 ; 20^{\circ}$ \\
\hline B2 - B3 & $176^{d} \quad \frac{2 h}{5}$ & $168 ; 55^{\circ}$ & $176^{\mathrm{d}} \quad 1 \frac{1}{3} \mathrm{~h}$ & $168 ; 33^{\circ}$ \\
\hline
\end{tabular}

the Era Nabonassar (Hipparchus had already determined at least the dates in the Egyptian calendar), the time (if not stated in the observation report) of mideclipse, and the longitudes of the Sun, the Moon, and the mean Moon according to Ptolemy's own tables. For our purposes it will suffice to list for each eclipse Ptolemy's calculated time interval between epoch (year 1 of Nabonassar, Thoth 1 , noon at Alexandria) and mid-eclipse, the equivalent modern 'astronomical' date, and Ptolemy's calculated solar longitude:

(A1) Time since epoch: 365 (Egyptian) years, 25 days, $18 \frac{1}{2}$ (equinoctial) hours, corrected by Ptolemy to $18 \frac{1}{4}$ hours for the equation of time. Date: -382 December $22 / 23 . \lambda_{\odot}=\neq 28 ; 18^{\circ}$.

(A2) Time since epoch: 365 years, 203 days, $8 \frac{1}{4}$ hours, corrected to $7 \frac{5}{6}$ hours. Date: -381 June $18 / 19 . \lambda_{\odot}=\square 21 ; 46^{\circ}$.

(A3) Time since epoch: 366 years, 15 days, $10 \frac{1}{6}$ hours, corrected to $9 \frac{5}{6}$ hours. Date: -381 December $12 / 13 . \lambda_{\odot}=\uparrow 17 ; 30^{\circ}$.

(B1) Time since epoch: 546 years, 345 days, 7 hours, corrected to $6 \frac{1}{2}$ hours. Date: -200 September 22. $\lambda_{\odot}=\mathrm{ml} 26 ; 6^{\circ}$.

(B2) Time since epoch: 547 years, 158 days, $13 \frac{1}{3}$ hours, no correction needed. Date: -199 March 19. $\left.\lambda_{\odot}=\right)\left(26 ; 17^{\circ}\right.$.

(B3) Time since epoch: 547 years, 334 days, $14 \frac{1}{4}$ hours, corrected to $13 \frac{3}{4}$ hours. Date: -199 September 11. $\lambda_{\odot}=\mathrm{ml} 15 ; 12^{\circ}$.

Ptolemy next computes the intervals in time and solar longitude separating the eclipses, which he juxtaposes with the values that Hipparchus assumed in his calculation of the parameters of the lunar model (Table 1).

As Ptolemy points out, there are significant differences between Hipparchus's figures and his own, both for the time intervals and for the longitudinal intervals. Ptolemy is correct in regarding his own data as more accurate, and in attributing Hipparchus's inconsistent results for the parameters of the lunar model to the errors in Hipparchus's intervals. ${ }^{19}$ But Ptolemy says nothing about the reason why Hipparchus arrived at such bad values; nor have modern historians put forward a satisfactory explanation..$^{20}$ After all, since Hipparchus's solar theory is supposed to have had exactly the same parameters as Ptolemy's, should it not have predicted exactly the same solar longitudes?

It would be easy to dismiss the difficulty by supposing that Hipparchus made computational errors in working out the intervals; but we should turn to this explanation only as a last resort, since other possible causes of the discrepancies can be tested, while casual arithmetical mistakes can seldom be traced. In the 
present case, moreover, we would have to suppose that Hipparchus made several mistakes in calculations that should not have been particularly difficult. In what follows I shall assume that the inaccuracies in the intervals had a methodical origin in the way that Hipparchus computed the times and solar longitudes for the eclipses. If this was so, then Hipparchus must have had a procedure for predicting solar positions that was substantially different from Ptolemy's tables of mean motion and anomaly.

\section{The Discrepancies in Time}

We know that Hipparchus successfully determined the dates of the eclipses according to an astronomical calendar; this must have been the most arduous stage in finding the time intervals between each pair of eclipses. The next step was to convert the reported times of the eclipses from seasonal into equinoctial hours; and here Hipparchus had some latitude in extracting a figure for the seasonal hours from the imprecise wording of some of the observational reports. ${ }^{21}$ Hipparchus would probably have converted the times using a Babylonian-style arithmetical table of seasonal day-lengths, where Ptolemy uses a more accurate table of oblique ascensions based on spherical trigonometry. ${ }^{22}$ In either kind of table, the extreme values of length of day at the solstices were a given quantity associated with the locality, and the length of day at the equinoxes was, of course, exactly 12 hours. For the observations in question, which all occurred near equinoxes or solstices, only negligible discrepancies would accrue from using an arithmetical table instead of Ptolemy's table.

The measurement of the radial ratio in the lunar model demands knowledge of the exact time of opposition, because the Moon's longitude is only then known, as being diametrically opposite the Sun's. But the observation reports do not give the time of opposition, i.e. mid-eclipse, except in the case of eclipse B3. In the case of eclipses A2 and B1 the mid-eclipse is deducible from the reported time of the beginning of obscuration and the eclipse's duration. For the others, the time of mid-eclipse has to be estimated from the reported time of the beginning and the eclipse's magnitude. Ptolemy assumes that the duration of the total eclipses, A3 and B2, will have been 4 equinoctial hours, while he ascribes a duration of $1 \frac{1}{2}$ equinoctial hours to the partial eclipse Al. These figures are to some extent arbitrary, and Hipparchus need not have made the same estimates.

A final step that can be taken to obtain more accurate values for the time intervals separating the middles of each pair of eclipses is the.correction for the 'equation of time', that is, the variation in the length of days caused by the solar anomaly and the obliquity of the ecliptic with respect to the equator. ${ }^{23}$ If Hipparchus neglected this correction, errors on the order of a fraction of an hour would have resulted, as can be seen from the corrections that Ptolemy applied to the intervals since epoch, which are listed above.

Hipparchus's calculation of the time intervals could therefore have diverged from Ptolemy's at several stages. In fact, one can obtain approximately the same intervals between the eclipses as Hipparchus found, if one reduces the estimate 
TABLE 2. A reconstruction of Hipparchus's time intervals.

\begin{tabular}{|c|c|c|c|c|c|}
\hline & $\underset{\Delta \mathrm{t}}{\text { Ptolemy's }}$ & $\begin{array}{l}\text { minus his } \\
\text { equation } \\
\text { of time }\end{array}$ & $\begin{array}{l}\text { corrected } \\
\text { for eclipse } \\
\text { duration }\end{array}$ & $\begin{array}{c}\text { Resulting } \\
\text { hypothetical } \\
\Delta \mathrm{t}\end{array}$ & $\underset{\Delta \mathrm{t}}{\operatorname{Hipparchus's}}$ \\
\hline $\mathrm{A} 1-\mathrm{A} 2$ & $177^{\mathrm{d}} 13 \frac{7}{12} \mathrm{~h}$ & $+\frac{11 b}{6}$ & & $=177^{\mathrm{d}} 13 \frac{3}{4} \mathrm{~h}$ & $177^{d} 13 \frac{3 \mathrm{~h}}{4}$ \\
\hline$A 2-A 3$ & $177^{\triangleleft} \quad 2^{\mathrm{h}}$ & $-\frac{1}{12}$ & $-\frac{1}{4} h$ & $=177 \mathrm{~d} \quad 1^{\frac{2}{3} \mathrm{~h}}$ & $177^{\mathrm{d}} \quad 1 \frac{2 \mathrm{~h}}{3}$ \\
\hline $\mathbf{B} 1-\mathbf{B} 2$ & $178^{\mathrm{d}} \quad 6 \frac{5 \mathrm{~s}}{6}$ & $-\frac{1}{2} h$ & $-\frac{1}{4}$ & $=178^{\mathrm{d}} \quad 6 \frac{1 \mathrm{th}}{\mathrm{h}}$ & $178^{d} 6^{h}$ \\
\hline $\mathbf{B} 2-\mathbf{B} 3$ & $176^{\mathrm{d}} \quad \frac{2 \mathrm{~h}}{\xi}$ & $+\frac{1}{2} h$ & $+\frac{1}{4}$ & $=176^{\mathrm{d}} \quad 1_{130}^{3} \mathrm{~h}$ & $176^{d} \quad 1 \frac{1}{3} \mathrm{~h}$ \\
\hline
\end{tabular}

of the duration of the total eclipses A3 to B2 to $3 \frac{1}{2}$ hours (which would be no less reasonable than Ptolemy's 4 hours), ${ }^{24}$ and neglects the equation of time. The effect of these hypothetical modifications to Ptolemy's time-intervals is shown in Table 2 . The agreement between the hypothetically reconstructed time intervals and Hipparchus's numbers is exact for the first eclipse triple, and fairly good for the second triple. If one treats the seasonal hours of the reports of eclipses B1, $\mathrm{B} 2$, and $\mathrm{B} 3$ as equivalent to equinoctial hours (a reasonable simplification since they all fall near equinoxes), the reconstructed intervals between these eclipses come to be $178^{\mathrm{d}} 6_{12}^{1 \mathrm{~h}}$ and $176^{\mathrm{d}} 1 \frac{1}{3}^{\mathrm{h}}$, so that only one of the four reconstructed intervals differs from Hipparchus's, and only by a negligible fraction of an hour at that.

In view of the success with which we have been able to 'correct' Ptolemy's time intervals to obtain Hipparchus's, it appears highly probable that Hipparchus did assume a shorter duration for total eclipses than Ptolemy's four hours when the reports gave only the time of beginning of obscuration, and that he did not correct the intervals for the equation of time. The latter is a significant point, since there appears to be no other evidence that Hipparchus was conscious of the inequality of solar days (or at any rate the possibility of correcting for it); there is even a distinct possibility that thd equation of time was Ptolemy's discovery. ${ }^{25}$ However, the explanation of the discrepancies in Hipparchus's time intervals casts no light on the discrepancies in the intervals of solar longitude, since no correlation holds between the signs of the differences applying to each pair of eclipses, and the greatest error in longitude that could result directly from an error of $\frac{3}{4} h$ would not exceed 2 minutes of arc.

\section{Varieties of Solar Tables}

A scheme of tables such as the mean motion and anomaly tables for the Sun in Ptolemy's Almagest exhibits a format and a theoretical basis that are more or less separable. In other words, Ptolemy's layout (tables of increments in mean motion for various time intervals, and a table of equation of centre) is not the only one by which longitudes could be predicted in accordance with his solar theory. It would be possible, for example, to make a list of dates of vernal equinoxes (when the Sun is at $r 0^{\circ}$ ) to be used with a 'template' listing solar longitude as a function of the time elapsed through the year following the equinox. Given no more than a few longitudes calculated by such a set of tables, 
we would have no way to prove that they were not derived from Ptolemy's tables. On the other hand, an identical layout might be made to present a pattern of anomalistic motion based on quite different theoretical assumptions, and this difference would become apparent in the longitudes predicted by means of such tables. Hence if Hipparchus's intervals in solar longitude were not thrown off by computational errors, there must have been a difference in theoretical basis between his method of predicting solar longitudes and Ptolemy's tables. This could be for various reasons. When he was working on the lunar theory Hipparchus may not yet have arrived at his 'final' values for the parameters of the solar model. Alternatively, while accepting the theoretical validity of the model just as Ptolemy preserves it, nevertheless for purposes of calculation he may have used methods or tables that approximated the anomalistic motion of the Sun without using the correct trigonometric formula for the equation of centre. If we restrict speculation to the varieties of methods attested elsewhere in ancient astronomy, the anomaly could have been represented by arithmetical series (the 'step' functions and 'zigzag' functions of Babylonian astronomy) or by a simple trigonometric function (e.g. the equation of centre could be proportional to the sine of the mean solar elongation from perigee, as in some Indian traditions).

Suppose that Hipparchus computed the solar longitudes for each eclipse from some sort of rule or table that, like Ptolemy's tables, represented solar longitude as a function (direct or indirect) of the time since the Sun was previously at its apogee. It will be convenient to express this time in degrees of mean solar motion, using Ptolemy's table of mean motions in Almagest III, 2. We use the following notations: $\lambda_{1}, \lambda_{2}, \lambda_{3}$ are the three longitudes of the Sun supposed to have been computed by Hipparchus for the three eclipses of each eclipse trio; $\delta_{1}$ and $\delta_{2}$ are the two known longitudinal intervals $\lambda_{2}-\lambda_{1}$ and $\lambda_{3}-\lambda_{2} ; \bar{\lambda}_{1}, \lambda_{2}, \bar{\lambda}_{3}$ are the mean solar longitudes for the three eclipses; $\bar{\delta}_{1}$ and $\bar{\delta}_{2}$ are the differences of mean longitude $\bar{\lambda}_{2}-\bar{\lambda}_{1}$ and $\bar{\lambda}_{3}-\bar{\lambda}_{2}$, which can be computed using Ptolemy's table from Hipparchus's time intervals between the eclipses; and $e_{1}, e_{2}$, and $e_{3}$ are the three equations of centre $\lambda_{1}-\bar{\lambda}_{1}, \lambda_{2}-\lambda_{2}$, and $\lambda_{3}-\bar{\lambda}_{3}$. The equations $e_{2}$ and $e_{3}$ are related to $e_{1}$ as follows:

$$
\begin{aligned}
& e_{2}=e_{1}+\left(\delta_{1}-\delta_{1}\right), \\
& e_{3}=e_{2}+\left(\delta_{2}-\delta_{2}\right) .
\end{aligned}
$$

For the first eclipse trio A1, A2, A3 we find (to the nearest second of arc)

$$
\begin{aligned}
& e_{2}=e_{1}-2 ; 8,50^{\circ} \text { and } \\
& e_{3}=e_{2}+0 ; 35,56^{\circ}=e_{1}-1 ; 32,54^{\circ} .
\end{aligned}
$$

Thus a difference in equation of $1 ; 32,54^{\circ}$ corresponds to the interval of solar mean motion

$$
\delta_{1}+\delta_{2}=349 ; 32,54^{\circ}=-10 ; 27,6^{\circ} \text {. }
$$

But so great a difference over about $10^{\circ}$ is impossible for any plausible solar equation function. In Ptolemy's equation table, Almagest III,6, the maximum difference over $12^{\circ}$ of mean motion (near perigee) is $0 ; 32^{\circ}$; while the maximum 
change of equation over $10^{\circ}$ resulting from the Babylonian System B zigzag function for solar motion is just under $0 ; 20^{\circ} .^{26}$ Hipparchus's longitudinal intervals for the first set of eclipses cannot have been found by taking the differences between solar longitudes that were calculated by any scheme expressible as a reasonably accurate mean motion corrected by an equation function. The excess of the change of equation over what it should have been (about $1^{\circ}$ ) suggests that the value for the length of the year implicit in Hipparchus's calculations was too great by nearly a day, and this is hard to believe unless the year length was not a conspicuous element in Hipparchus's solar scheme.

Turning to the second set of eclipses, B1, B2, B3, we find

$$
\begin{aligned}
& e_{2}=e_{1}+4 ; 38,38^{\circ} \text { and } \\
& e_{3}=e_{2}-4 ; 58,35^{\circ}=e_{1}-0 ; 19,57^{\circ} .
\end{aligned}
$$

The difference in mean motion between $\mathrm{B} 1$ and $\mathrm{B} 3$ is $349 ; 12,58^{\circ}=-10 ; 47,2^{\circ}$. But eclipses B1 and B3 occurred a few days before the autumnal equinox, so that the Sun was just past half way between apogee (for Ptolemy and Hipparchus, $\square 5 ; 30^{\circ}$ ) and perigee. At this stage of the Sun's revolution, the solar equation attains its maximum, and the rate of change of the equation is small. In the corresponding part of Ptolemy's equation table, the equation changes by a mere $0 ; 8^{\circ}$ over $12^{\circ}$ of mean motion. In the scheme that Hipparchus used to produce the longitudinal intervals for the second eclipse trio, the rate of change of the solar equation cannot have tended to zero between the apogee and perigee, which means that the solar velocity according to the scheme was discontinuous. This conclusion rules out of consideration tables based on trigonometric functions, like Ptolemy's equation table or the Indian sinusoidal equations, as well as tables based on a linearly varying solar velocity.

\section{The 'System A' Hypothesis}

The only remaining hypothesis justified by our present knowledge of ancient astronomical methodology is a 'step' function in which the solar velocity assumes constant values over fixed zones of the ecliptic. Column B of the Babylonian System A lunar ephemerides provides the obvious prototype for such a scheme. ${ }^{27}$ Each line of a Babylonian lunar ephemeris represents one synodic month; thus Column B gives the Sun's longitude for a sequence of consecutive conjunctions or oppositions. The basic System A pattern of solar motion is simple: over the $194^{\circ}$ between longitudes $\mathrm{m} / 13^{\circ}$ and $) 27^{\circ}$ the Sun is supposed to travel $30^{\circ}$ per synodic month, while it travels only $28 ; 7,30^{\circ}$ (i.e. $28 \frac{1}{8}^{\circ}$ ) per month for the $166^{\circ}$ completing its circuit of the ecliptic (Figure 2). This 'solar model' works reasonably well because the Moon's apparent motion is so much faster than the Sun's that the progress in longitude from one syzygy to the next is predominantly a function of the Sun's velocity, and hence of the Sun's longitude. ${ }^{28}$ Given the Sun's longitude at (say) one opposition, the longitude of the next opposition is found simply by adding the constant prescribed for the zone that the Sun is in, unless this addition would bring the Sun into the other 


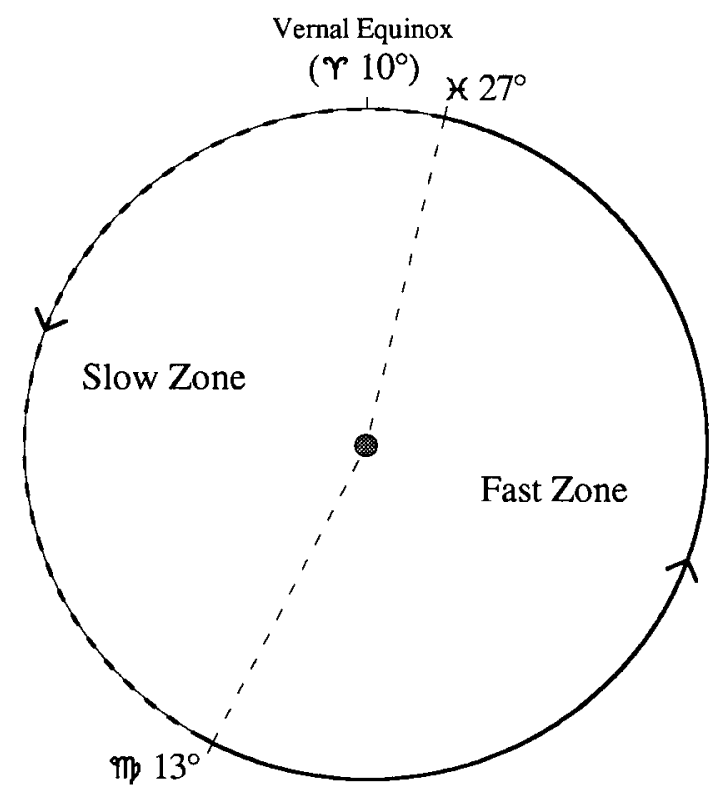

FIG. 2. The Babylonian System A solar scheme (fast zone: $30^{\circ} / \mathrm{syn}$. m., slow zone: $28 \frac{1}{8} / \mathrm{syn}$. m.).

zone. In that case, one determines the fraction of the synodic month required to bring the Sun to the boundary between zones (at the velocity for the first zone), and applies the remaining fraction at the velocity of the second zone to find the Sun's progress after the boundary. The length of each zone, divided by the constant advance in longitude per synodic month for that zone, gives the number of synodic months required to traverse the zone; hence the System $A$ rules imply a year length in synodic months (which is reasonably accurate):

1 year $=\frac{194}{30}+\frac{166}{28 ; 730}$, that is, $12 ; 22,8$ synodic months $(\approx 365 ; 15,38$ days $)$.

The midpoints of the slow and fast arcs, $\square 20^{\circ}$ and $\hat{f} 20^{\circ}$, define the 'apsidal line' of the scheme. Since the vernal equinoctial point is set at $r 10^{\circ}$ in System A, the 'apogee' falls $70^{\circ}$ after the equinoctial point (contrast Hipparchus's value of $65 \frac{1}{2}^{\circ}$ for this interval).

An interval between eclipses must comprise a whole number of synodic months, so that the System A rules for computing solar longitudes for consecutive oppositions would have had an obvious convenience for Hipparchus's computation of the longitudes of eclipses separated by fairly short times. He would need to find the longitude of one of the three eclipses by some other means (e.g. proximity to an equinox or solstice), and the remaining two would follow by simple arithmetic. Also, the occurrence of fractions of $\frac{1}{8}^{\circ}$ in Hipparchus's two longitudinal intervals A1-A2 and A2-A3 make it tempting to see whether these numbers can be explained by compounding intervals of motion at $30^{\circ}$ and at $28 \frac{1}{8}^{\circ}$ per month over consecutive synodic months. Because of the 
times of year of the eclipses, the solar longitudes for eclipses A1 and A3 must fall in the middle of the fast zone of the ecliptic, while the longitude for A2 falls in the middle of the slow zone. The interval for A1-A2, 173- $\frac{1}{8}$, should decompose into a certain number, $a$, of synodic months of motion at $30^{\circ}$ per month, followed by (6-a) synodic months of motion at $281^{\circ}$ per month; and similarly the interval for $\mathrm{A} 2-\mathrm{A} 3,175 \frac{1}{8}$, should decompose into some number $b$ of months of motion at $28 \frac{1}{8}^{\circ}$ per month followed by $(6-b)$ months at $30^{\circ}$ per month. Hence $a=2 \frac{1}{5}$, and $b=2 \frac{3}{5}$ (exactly).

Next we determine where the boundaries between the zones of fast and slow solar motion must fall on the ecliptic if they are to divide the six-month intervals into sections of $a,(6-a), b$, and $(6-b)$ months. During $(6-a)+b$ months the Sun must have travelled through the entire slow zone, which therefore has a length of $(6+b-a) \times 28 \frac{1}{8}^{\circ}$, or exactly $180^{\circ}$.

The foregoing analysis is, of course, guaranteed to yield some division of the ecliptic, whether or not the intervals of solar longitude on which it is based were originally computed by a scheme dividing the ecliptic into two zones associated with the System A solar velocities. If the intervals had been computed according to the Babylonian scheme itself, a slow zone of exactly $166^{\circ}$ should have been found by our analysis, and conversely, finding such a zone would have been strong confirmation that the Babylonian scheme was used. Intervals derived by some other reasonably accurate method would lead to a zone division approximating the Babylonian one; for example, Ptolemy's values for the same intervals A1-A2 and A2-A3, based on his own tables, would yield a slow zone of $162^{\circ}$. What we have obtained from Hipparchus's intervals is a division that both diverges far from the expected values, and exhibits a strikingly simple symmetry: two zones exactly bisecting the ecliptic. This is very unlikely to be an accident. The conclusion is unavoidable that Hipparchus calculated the longitudal intervals between eclipses $\mathrm{A} 1, \mathrm{~A} 2$, and $\mathrm{A} 3$ by an adaptation of the Babylonian System A solar scheme in which the zones were made equal, but the Babylonian velocities associated with the zones were retained. A consequence of this modification was that the year length embedded in the scheme was now inaccurate:

$$
1 \text { year }=\frac{180}{30}+\frac{180}{28,7,30} \text {, that is, } 12 ; 24 \text { syn. } \mathrm{m} .(\approx 366 ; 11 \text { days }) \text {, }
$$

and it is precisely this wrong year length that accounts for the gross inaccuracy of Hipparchus's first pair of longitudinal intervals.

A further datum that can be extracted from our analysis of Hipparchus's intervals is the situation of the three solar longitudes relative to the zone boundaries (Figure 3). The longitude of the eclipse A1 was $2 \frac{1}{5} \times 30^{\circ}=66^{\circ}$ before the boundary that begins the slow zone; that of A2 was $3 \frac{4}{5}^{\circ} \times 28 \frac{1}{8}^{\circ}=$ $106 \frac{7}{8}^{\circ}$ after the same boundary; and that of $\mathrm{A} 3$ was $3 \frac{2}{5} \times 30^{\circ}=102^{\circ}$ after the other boundary, or $78^{\circ}$ before the first boundary. The interval between $A 1$ and the midpoint of the slow arc is $156^{\circ}$. Now to use the (modified) Babylonian scheme at all, Hipparchus had to have the longitude of one of the eclipses as an initial value from which to find the others. This was probably $\mathrm{Al}$, because this eclipse occurred very close to the winter solstice, so that the Sun's longitude 


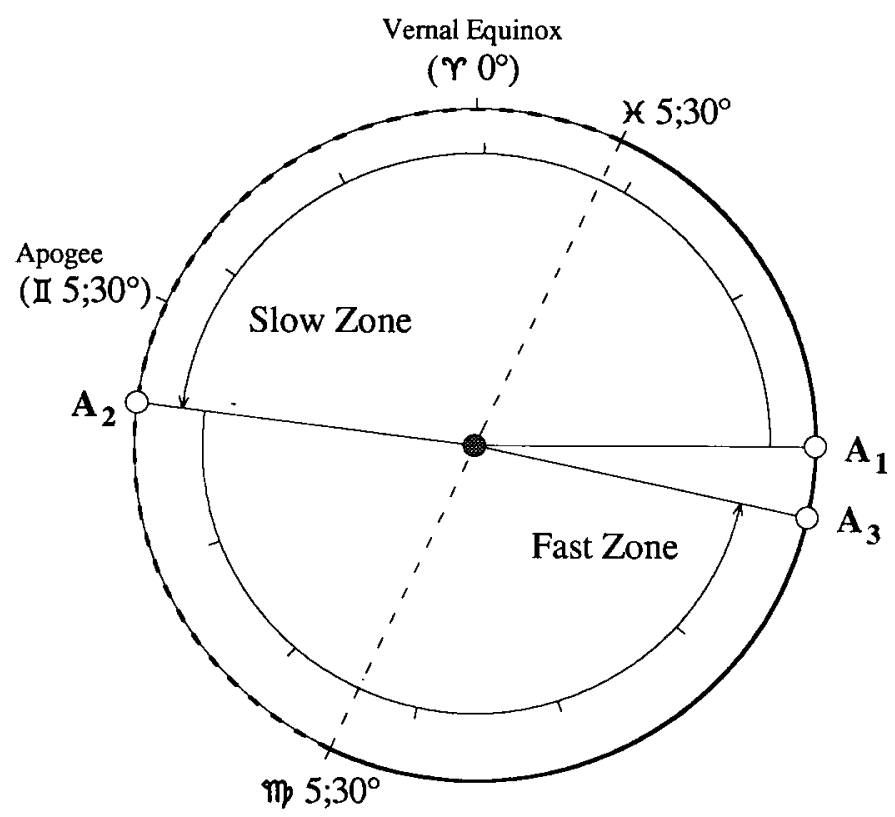

FIG. 3. Hipparchus's first scheme and eclipse trio (fast zone: $30^{\circ} / \mathrm{syn}$. m., slow zone: $28 \frac{1}{8}^{\circ} / \mathrm{syn}$. m.).

would be known as nearly $r 0^{\circ}$ (Ptolemy calculates it as $f 28 ; 18^{\circ}$ ). If Hipparchus chose a longitude of about $r 0^{\circ}$ for $\mathrm{A} 1$, then the midpoint of the slow arc of his scheme would have fallen at about $\square 6^{\circ}$, and this is in good agreement with the longitude that Hipparchus found for the solar apogee, $\square 5 ; 30^{\circ}$. It thus appears that Hipparchus's adaptation of the System A solar scheme was made after his determination of the solar eccentricity and apsidal line, and that his modification of the zone boundaries was partly motivated by a wish to line the zones up with his apsidal line, while also moving the equinoctial points from $\gamma$ $10^{\circ}$ and $\bumpeq 10^{\circ}$ (the System A convention) to the beginning of their signs.

\section{The Second Trio of Eclipses}

There are reasons for doubting whether Hipparchus's two measurements of the lunar radial ratio were carried out in a single work. Ptolemy tells us that the first calculation, using the eclipses of $-382 / 381$, was made according to the eccentric hypothesis, and the second, using the eclipses of $-200 / 199$, according to the epicyclic hypothesis. ${ }^{29}$ Now if the point of doing the calculation twice was to confirm the constancy of the ratio (and hence the validity of the hypothesis), there would have been no sense in using different versions of the hypothesis each time; while if Hipparchus's purpose was to show the equivalence of the eccentric and epicyclic hypotheses in a concrete way, he should have used the same eclipses both times. ${ }^{30}$ We also know that Hipparchus adopted the second measurement in his work "On the sizes and distances", so that it appears that he considered the second measurement to have superseded the first. ${ }^{31}$ Even the 
form in which Hipparchus expressed the longitudinal intervals in the two calculations is different: in the first, they display the conspicuous fractions of $\frac{1}{8}{ }^{\circ}$ that gave away their derivation from the System A speeds, while in the second, they are given as conventional degrees and minutes. It is not surprising, therefore, to find that the second pair of longitudinal intervals was not computed by the flawed solar scheme used for the first set. This is obvious from the interval B1-B2, $180 ; 20^{\circ}$, which exceeds the $180^{\circ}$ that the Sun could progress in six synodic months at a speed of $30^{\circ}$ per month. Nevertheless our earlier analysis of the intervals of the second trio into differences of mean motion and equation of centre led to the conclusion that these too had to be computed by a method with a discontinuously varying equation of centre, i.e. some sort of 'System A' scheme with zones of constant speed.

In approaching Hipparchus's longitudinal intervals for the second trio of eclipses, we set out with the simplest hypothesis, that his method was substantially the same as for the first trio, except that he used different values for the Sun's fast and slow velocities in the two halves of the ecliptic. We want to find $f$ and $s$, the number of degrees per synodic month that the Sun is supposed to travel in the fast and slow zones, which we assume to begin at mp $5 ; 30^{\circ}$ (i.e. $155 ; 30^{\circ}$ ) and $)\left(5 ; 30^{\circ}\right.$ (i.e. $335 ; 30^{\circ}$ ) respectively. Let $\lambda_{1}$ be the Sun's assumed longitude at the first eclipse, B1, which should fall within the fast zone. The differences of solar longitude for the six-month intervals B1-B2 and B2-B3 are $180 ; 20^{\circ}$ and $168 ; 33^{\circ}$ respectively. These data give rise to the following equations:

$$
\begin{aligned}
& \frac{\left(335 ; 30^{\circ}-\lambda_{1}\right)}{f}+\frac{\left(180 ; 20^{\circ}-335 ; 30^{\circ}+\lambda_{1}\right)}{s}=6, \\
& \frac{\left(360^{\circ}+155 ; 30^{\circ}-\lambda_{2}\right)}{s}+\frac{\left(168 ; 33^{\circ}-155 ; 30^{\circ}+\lambda_{2}\right)}{f}=6,
\end{aligned}
$$

where $\lambda_{2}=\lambda_{1}+180 ; 20^{\circ}$. The same equations may be restated thus:

$$
\begin{aligned}
& \left(335 ; 30^{\circ}-\lambda_{1}\right) s+\left(204 ; 50^{\circ}+\lambda_{1}-360^{\circ}\right) f=6 f s, \\
& \left(193 ; 23^{\circ}+\lambda_{1}-360^{\circ}\right) s+\left(335 ; 10^{\circ}-\lambda_{1}\right) f=6 f s,
\end{aligned}
$$

so that

$$
\begin{aligned}
& f=\frac{335 ; 30^{\circ}-\lambda_{1}}{6}+\frac{\left(204 ; 50^{\circ}+\lambda_{1}-360^{\circ}\right)\left(142 ; 7^{\circ}-2 \lambda_{1}+360^{\circ}\right)}{6\left(130 ; 20^{\circ}-2 \lambda_{1}+360^{\circ}\right)}, \\
& s=\frac{\left(130 ; 20^{\circ}-2 \lambda_{1}+360^{\circ}\right) f}{142 ; 7^{\circ}-2 \lambda_{1}+360^{\circ}} .
\end{aligned}
$$

Eclipse B1 occurred approximately four days before the autumnal equinox. Assuming, therefore, that $\lambda_{1} \approx 176^{\circ}$, we find $f \approx 30 ; 21,5^{\circ}$, and $s \approx 27 ; 58,8^{\circ}$. These speeds are nearly in the same ratio as the maximum and minimum apparent speeds that would result from Hipparchus's measurement of the solar eccentricity as $\frac{1}{24}$ the radius of its orbit:

$$
\frac{f}{s} \approx 1.085,
$$




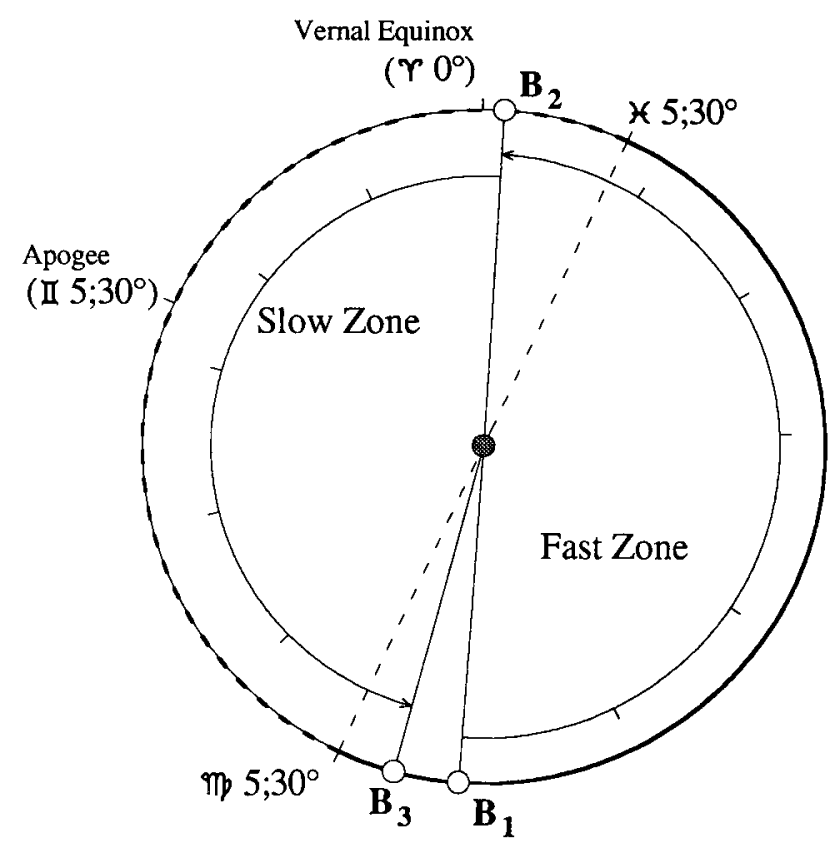

FIG. 4. Hipparchus's second scheme and eclipse trio (fast zone: $\sim 30 ; 21 \%$ syn. m., slow zone: $\sim 28 ; 58^{\circ}$ /syn. m.).

$$
\frac{1+\frac{1}{24}}{1-\frac{1}{24}} \approx 1.087
$$

They also imply an approximation of the length of the year that is satisfactory for computations over the fairly short intervals that Hipparchus is working with: ${ }^{32}$

$$
\frac{180}{30 ; 21,5}+\frac{180}{27 ; 58,8} \approx 12 ; 21,59 \text { syn. m. }(\approx 365 ; 12 \text { days }) \text {. }
$$

Hipparchus's second set of longitudinal intervals thus determines a 'System A' solar scheme with speeds in approximate agreement with the eccentricity of his solar model, where these speeds are supposed to apply over $180^{\circ}$ zones centred on the apsidal line that he established for the Sun's eccentre (Figure 4). If his figures had been originally computed in a radically different way, it is unlikely that such plausible speeds and so accurate a year length would have resulted from this analysis. For example, if we tried to explain Ptolemy's intervals, $180 ; 11^{\circ}$ and $168 ; 55^{\circ}$, as products of such a scheme, we would arrive at speeds of about $30 ; 19^{\circ}$ and $28 ; 2^{\circ}$ per synodic month (hence $f / s \approx 1.081$ ), and a year length of about $12 ; 21,39$ synodic months $(\approx 364 ; 59$ days). The reconstruction of the scheme behind Hipparchus's second pair of longitudinal intervals cannot be regarded as certain in every respect; too many of the factors involved are known 
only approximately (including the intervals themselves, which Hipparchus probably truncated to the nearest minute). But we have established (1) that the second set was calculated according to a solar scheme that assumed zones of constant speed, (2) that this scheme was not identical to the scheme used for the first set of intervals, and (3) that the second scheme was probably a simple modification of the first (as the first was a modification of the Babylonian rules) to bring it into still closer accord with Hipparchus's solar model and (incidentally) to eliminate the systematic error in the first scheme.

\section{The Observations of $-127 / 126$}

Let us now return to the three Hipparchian observations of the Moon's elongation from the Sun that Ptolemy quotes in V,3 and V,5:

(C1) He [i.e. Hipparchus] says that he made the observation in the fifty-first year of the Third Kallippic Cycle, Epiphi [XI] 16 in the Egyptian calendar [ -127 August 5], when $\frac{2}{3}$ of the first hour had passed. "The [lunar] speed was [that of day] 241", he says, "and while the Sun was sighted in $\Omega 87_{12}^{\circ}$ the apparent position of the Moon was $\varnothing 12 \frac{1}{3}^{\circ}$, and its true position was approximately the same". ${ }^{33}$

(C2) Now Hipparchus records that he observed the Sun and the Moon with his instruments in Rhodes in the 197th year from the death of Alexander, Pharmouthi [VIII] 11 in the Egyptian calendar [-126 May 2], at the beginning of the second hour. He says that while the Sun was sighted in $\gamma$ $7 \frac{34^{\circ}}{4}$, the apparent position of the centre of the Moon was $)\left(21 \frac{20}{3}\right.$, and its true position was $)\left(21 \frac{1}{3}+\frac{1}{8}^{\circ} .{ }^{34}\right.$

(C3) Similarly, ... we have again selected from the distances [between Sun and Moon] observed by Hipparchus, as already mentioned, in Rhodes, the observation he made in the same year [as the preceding one], being the 197th year from the death of Alexander, Payni [X] 17 in the Egyptian calendar [ -126 July 7], at $9 \frac{1}{3}$ hours. He says that while the Sun was sighted at $\sigma 010_{10}^{9}$ the apparent position of the Moon was $\Omega 29^{\circ} .{ }^{35}$

The question we have to settle concerning these observations (which Ptolemy says that he excerpted from a series of such lunar elongations observed by Hipparchus) is whether Hipparchus computed or measured the solar longitudes at which the Sun was 'sighted'. The variations on the System A rules described above are designed to generate solar longitudes only for a sequence of consecutive conjunctions or oppositions, but of course it would be an easy matter to adapt them to the problem of daily motion by dividing the progress per synodic month prescribed for the two zones by the length of the synodic month in days. The proof that Hipparchus did not do this to compute these longitudes is easy. If they were computed according to a scheme with two zones of constant speed, the solar longitudes of all three observations would fall within the slow zone. Let the dates of the observations be $t_{1}, t_{2}$, and $t_{3}$, and the corresponding longitudes $\lambda_{1}, \lambda_{2}$, and $\lambda_{3}$. We can replace the date $t_{1}$ of $\mathrm{Cl}$ with a 
date $t_{1}{ }^{\prime}$ one year (i.e. approximately $365 \frac{1}{4}$ days) later when the Sun had the same longitude, so that the three longitudes are brought into a single traversal of the zone. The differences between the longitudes should then be proportional to the differences between their dates; and they clearly are not:

$$
\begin{aligned}
& \frac{\left(\lambda_{1}-\lambda_{3}\right)}{\left(t_{1}^{\prime}-t_{3}\right)} \approx \frac{27 ; 41^{\circ}}{28 ; 52 \text { days }} \approx 0 ; 57,32^{\circ} / \text { day }, \\
& \frac{\left(\lambda_{3}-\lambda_{2}\right)}{\left(t_{3}-t_{2}\right)} \approx \frac{63 ; 9^{\circ}}{66 ; 24 \text { days }} \approx 0 ; 57,4^{\circ} / \text { day. }
\end{aligned}
$$

Nor can a plausible scheme assuming continuously varying solar speed explain Hipparchus's numbers. According to Hipparchus's solar model, the Sun reaches its apogee $\left(\Pi 5 ; 30^{\circ}\right.$ ) approximately $67 \frac{2}{3}$ days after the vernal equinox, and any tables that make the Sun's daily motion vary continuously between the maximum and minimum dictated by the model would predict a longitude of $\Pi$ $5 ; 30^{\circ}$ at about this many days past equinox. Hipparchus observed the vernal equinox as having occurred on - 127 March 23 at sunset, and he would have predicted (if he did not also observe) the recurrence of the equinox on -126 March 23/24 at midnight. ${ }^{36}$ Hence we know both the elongations of the three solar longitudes $\lambda_{1}, \lambda_{2}, \lambda_{3}$ from the apogee, and the intervals separating $t_{1}, t_{2}$, and $t_{3}$ from the date when the Sun was at apogee:

$$
\begin{aligned}
& \frac{\left.\lambda_{1}-65 ; 30^{\circ}\right)}{\left(t_{1}-67 ; 40 \text { days }\right)} \approx \frac{65 ; 5^{\circ}}{66 ; 50 \text { days }} \approx 0 ; 58,26^{\circ} / \text { day }, \\
& \frac{\left(\lambda_{2}-65 ; 30^{\circ}\right)}{\left(t_{2}-67 ; 40 \text { days }\right)} \approx \frac{27 ; 45^{\circ}}{28 ; 24 \text { days }} \approx 0 ; 58,38^{\circ} / \text { day }, \\
& \frac{\left(\lambda_{3}-65 ; 30^{\circ}\right)}{\left(t_{3}-67 ; 40 \text { days }\right)} \approx \frac{35 ; 24^{\circ}}{38 \text { days }} \approx 0 ; 55,54^{\circ} / \text { day. }
\end{aligned}
$$

The quotients, which should represent the mean solar daily motion between the apogee and the date of observation, obviously do not behave as they should: the speed ought to increase gradually with increasing elongation, and here it appears to drop abruptly between $27 ; 45^{\circ}$ and $35 ; 24^{\circ}$ from apogee. All in all, it seems most probable that at least one of Hipparchus's solar longitudes was observed rather than predicted. ${ }^{37}$

\section{Retrospect}

That Greek astronomers, and specifically Hipparchus, had access to elements of Babylonian mathematical astronomy has been known since Kugler found the fundamental parameters of Hipparchus's lunar theory in the System B ephemerides. ${ }^{38}$ Until recently it appeared safest to assume that only a handful of parameters, period relations, and simple schemes were transmitted from Babylonian to Greek astronomy. But since the discovery of a Greco-Egyptian papyrus fragment from the Roman period that contains what can only be interpreted as part of a Babylonian System B lunar ephemeris, ${ }^{39}$ it must now be conceded that the most complex systems of the Babylonian ephemerides were 
substantially transmitted, and moreover that the Babylonian procedures were actually in use centuries after this transmission must have taken place. Yet at the same time there is no evidence to suggest that the Greeks possessed more than a superficial knowledge of the rationale or the empirical bases behind the Babylonian schemes, or even of the meaning of every column.

Babylonian astronomy thus comes to figure more and more prominently in the background of Hipparchus's work. In his efforts to establish quantitative geometrical models for the celestial motions, Hipparchus was able to draw not just on a body of observation reports, both Greek and Babylonian, but also on an already existing quantitative theory that, while obviously not founded on right geometric principles, nevertheless furnished impressively accurate predictions of the observable phenomena. Babylonian theory could serve as a guide indicating what to look for in observations, and when to look; and if observations were lacking, the theory could even serve as a 'vicarious hypothesis' simulating observed data. For example, in his Commentary on the Phenomena of Aratus and Eudoxus, where Hipparchus wishes to refute the notion (apparently common in earlier Greek astronomy) that the Sun has a latitudinal motion with respect to the ecliptic, he appeals to the lunar eclipse predictions of the "astrologoi", which, he says, presuppose no solar latitude and yet are generally accurate to within two digits of eclipse magnitude. The only methods of eclipse prediction that were known in Hipparchus's time and to which his description could apply are the Babylonian procedures. ${ }^{40}$

The solar theory has always appeared to be one area where Babylonian data did not enter into Hipparchus's calculations. As Ptolemy portrays it, Hipparchus's theory was derived solely from observations of solstices and equinoxes by himself and by previous Greek astronomers (Meton and Euctemon, Aristarchus, Archimedes). Yet it may be wondered, given the difficulty of making precise equinox and (especially) solstice observations, whether Hipparchus, or any other Greek astronomer, could have discovered the inequality of the seasons and the solar anomaly by this route. Recently it has been pointed out that Hipparchus's allegedly observed value, $94 \frac{1}{2}$ days, for the time between the vernal equinox and the summer solstice can be derived from the Babylonian System A speed for the slow zone in which this season entirely falls, combined with the System B length of the synodic month that Hipparchus is known to have used:41

$$
\frac{90^{\circ}}{28_{8}^{10} / \text { syn. } m .} \times \frac{29 ; 31,50,8,20 \text { days }}{1 \text { syn. } m .}=94 ; 29,52, \ldots \text { days } \approx 94 \frac{1}{2} \text { days. }
$$

Although it cannot be proved that Hipparchus obtained his interval in this way, the hypothesis of Babylonian derivation is supported by the fact that, while Hipparchus's observed vernal equinoxes (reported in Almagest III, 1) are all reasonably accurate, the summer solstices actually fell about $\frac{1}{3}$ day earlier. Our having shown above that Hipparchus knew and used an adaptation of the System A solar scheme adds still further plausibility to this conjecture. In fact, Ptolemy never actually attributes a solstice observation to Hipparchus, ${ }^{42}$ and even if Hipparchus did attempt to observe one or more summer solstices, the 
expectation that the summer solstice would occur $94 \frac{1}{2}$ days after the vernal equinox could have biased his measurements.

Hipparchus must have written the work in which he determined the parameters of the solar model, using the observed dates of the vernal and autumnal equinox and the problematic summer solstice, after -145 , the first year for which he had observations of both equinoxes (the last such year, according to Ptolemy's list of his observations, was -142$).{ }^{43}$ His deduction of the eccentricity and longitude of the apogee was along similar lines to Ptolemy's in Almagest III, 4 , but sufficiently different in its details to justify Ptolemy's decision "to display the theorem worked out according to our own numerical solution". ${ }^{44}$ At this time Hipparchus did not compose tables of solar motion. His solar model was ostensibly incomplete: he had no confirmed measure of the exact length of the year, and no observational evidence that the season lengths (and hence the apsidal line) remained fixed over long periods. The testimony of the Babylonian lunar systems was open to two interpretations. On the one hand, these systems operated on the assumption that the pattern of solar speed maintained a fixed pattern with respect to the zodiac (exactly in System A, with its fixed zones, very nearly in System B, where the longitude corresponding to the minimum solar speed shifts by a few seconds of arc per year). On the other hand, the season lengths predicted by the Babylonian systems, as well as the longitudes that should have corresponded to the solar apogee, did not match Hipparchus's data. When subsequently Hipparchus needed to extrapolate the behaviour of the solar model to observations before his own time, he adopted the Babylonians' theoretical supposition that the Sun's anomalistic period coincided with the year, instead of deducing a (spurious) long-term shift by comparison of the specific predictions of the Babylonian theory with his own observations.

Essentially the same fundamental theorem underlies both Hipparchus's measurement of the ratio of radii in the lunar model and his determination of the solar model; if the periods of the revolutions in a simple eccentric or epicyclic model are approximately known, and the apparent longitude of the body is given at three given times, the relative dimensions and configuration of the model can be determined. The first application of this theorem to the lunar model (which at this time Hipparchus chose to think of as a simple eccentre) came probably not long after the establishment of the solar model. Hipparchus had at his disposal the three Babylonian eclipse reports of $-382 / 381$, from which he was able to find the times of three oppositions. To obtain the corresponding longitudes, he first had to extrapolate the dates of the equinoxes and solstices back to these years. My guess is that he took the date of the winter equinox predicted by his model for (say) $-145,{ }^{45}$ and counted back by 236 years of exactly $365 \frac{1}{4}$ days:

Vernal equinox observed - 145 March $24=$ Nabonassar 602 VI 27, 6 a.m.; winter solstice predicted $90 \frac{1}{8}$ days earlier = Nabonassar 602 III 27, 3 a.m.; 236 years $=236 \times 365 \frac{1}{4}$ days $=236$ years +59 days; winter solstice predicted Nabonassar 366 I 28, 3 a.m.

Since this predicted solstice practically coincides with the time of mid-eclipse of 
the first eclipse A1 (Nab. 366 I 27, 6 a.m.). Hipparchus simply assumed that the Sun's longitude was approximately $r 0^{\circ}$.

Now to find the other two longitudes, Hipparchus did not, of course, work out a set of solar tables from his solar theory; he took over the standing (and reasonably reliable) procedure of System A for predicting longitudes of consecutive oppositions. But Hipparchus knew that the Babylonian conventions for reckoning longitudes were different from his own, and furthermore he had himself determined the longitude of the solar apsidal line, which should act as a line of symmetry in the pattern of solar speeds along the ecliptic. It must have seemed to Hipparchus a minimum and obvious adjustment to change the zones of the System A scheme so that they would be centred on his own apsidal line; and at the same time, he made the zones equal. Either Hipparchus did not realize that the latter modification (motivated, we must suppose, by considerations of simplicity and symmetry) would introduce a systematic error in the predicted longitudes, or he thought any resulting inaccuracy would be negligible. The mistake is more comprehensible if we recall that Hipparchus's adaptation of the System A rules was probably designed specifically for this one application to the lunar theory.

In his new arrangement of the zones, the estimated longitude for eclipse Al falls about $5 \frac{1}{2}^{\circ}$ before the end of the fast zone. Hipparchus took this interval as a round $6^{\circ}$, which makes for easier computation. The longitudes for A2 and A3 would have resulted from the following calculations:

\begin{tabular}{|c|c|c|}
\hline $\begin{array}{l}\text { ongitude at } \mathrm{Al} \\
2 \text { syn. } \mathrm{m} .\end{array}$ & $\begin{array}{r}269 \frac{11^{\circ}}{2} \\
+60^{\circ} \\
\end{array}$ & $=2 \times 30^{\circ} /$ syn. $\mathrm{m}$. \\
\hline progress to boundary & $\begin{array}{l}329 \frac{1}{2}^{\circ} \\
+6^{\circ} \\
\end{array}$ & $=\frac{1}{5}$ syn. m. $\times 30^{\circ} /$ syn. $\mathrm{m}$ \\
\hline remainder of syn. m. & $\begin{array}{r}335 \frac{1}{2}^{\circ} \\
+22 \frac{1}{2}^{\circ} \\
\end{array}$ & $=\frac{4}{5}$ syn. m. $\times 281^{\circ} /$ syn. $m$ \\
\hline 3 synodic months & $\begin{array}{r}358^{\circ} \\
+84 \frac{3}{8} \\
\end{array}$ & $=3$ syn. $\mathrm{m} . \times 28 \frac{1}{8}^{\circ} /$ syn. $\mathrm{m}$. \\
\hline $\begin{array}{l}\text { longitude at } \mathrm{A} 2 \\
2 \text { syn. } \mathrm{m} .\end{array}$ & $\begin{array}{r}82 \frac{3}{8}{ }^{\circ} \\
+566_{4}^{\circ} \\
\end{array}$ & $\begin{array}{l}\left(=173-\frac{10}{8} \text { past } \mathrm{A} 1\right) \\
=2 \times 28 \frac{1}{8} \circ / \text { syn. m. }\end{array}$ \\
\hline progress to boundary & $\begin{array}{r}138 \frac{5}{8} 0^{\circ} \\
+16 \frac{78^{\circ}}{8} \\
\end{array}$ & $=\frac{3}{5}$ syn. m. $\times 28 \frac{1}{8}^{\circ} /$ syn. m. \\
\hline remainder of syn. m. & $\begin{aligned} & 155 \frac{1}{2}^{\circ} \\
&+ 12^{\circ} \\
&\end{aligned}$ & $=\frac{2}{5}$ syn. m. $\times 30^{\circ} /$ syn. m. \\
\hline 3 synodic 1 & $\begin{array}{r}167 \frac{1}{2}^{\circ} \\
+90^{\circ} \\
\end{array}$ & $=3$ syn. $\mathrm{m} . \times 30^{\circ} /$ syn. $\mathrm{m}$. \\
\hline ongi & $257 \frac{1}{2}^{\circ}$ & $\left(=175 \frac{1}{8}^{\circ}\right.$ past $\left.A 2\right)$ \\
\hline
\end{tabular}


Using the longitudinal intervals found between the three eclipses, Hipparchus calculated the eccentricity in the lunar model by a method corresponding in its broad outlines to Ptolemy's method in Almagest IV, 6, arriving at the ratio $327 \frac{2}{3}: 3144 .{ }^{46}$

The reasons why Hipparchus decided to publish a second measurement of the radial ratio in the lunar model (now treated as the epicycle radius in an epicyclic model) can only be guessed. Perhaps Hipparchus had subsequently come across the reports of the three eclipses observed at Alexandria in $-200 / 199$, and judged them to be superior to the Babylonian reports. Or he might have found ways to improve the accuracy of the calculation of the ratio. ${ }^{47} \mathrm{By}$ this time, Hipparchus had probably confirmed the Babylonian period relations that determined the periods of revolution in his lunar model (though precise values for these periods are not necessary in the measurement of the radial ratio). ${ }^{48}$

In any case, Hipparchus had to dust off his adapted System A method of computing the solar longitudes for the new application, and at this point he realized that, in addition to realigning the zones according to his theoretical apsidal line, he ought to make the speeds prescribed for the zones correspond to the eccentricity of his model. Exactly what speeds he chose, and how he derived them, is not certain. I suggest that he assumed that the apparent solar speed was in inverse proportion to its distance from the Earth, and assigned to the two zones the maximum and minimum speeds resulting from an eccentricity of $1: 24$. These would have turned out to be approximately $30 ; 22 \% \mathrm{syn}$. m. and $27 ; 56^{\circ} /$ syn. $\mathrm{m}$. (the exact values would depend on the number of synodic months assumed to be in one year). In the analysis of Hipparchus's longitudinal intervals, we found $30 ; 21,5^{\circ} / \mathrm{syn}$. m. and $27 ; 58,8^{\circ} / \mathrm{syn}$. m. as possible values for the zone speeds, on the supposition that he assigned a longitude of $m=26^{\circ}$ to eclipse B1, so I will use these speeds in the following 'restoration' of Hipparchus's calculations:

longitude at B1

5 syn. m.

\begin{tabular}{|c|c|c|}
\hline & & \\
\hline progress to boundary & $\begin{array}{l}327 ; 45^{\circ} \\
+7 ; 45^{\circ} \\
\end{array}$ & $=0 ; 15,19$ syn. $\mathrm{m} . \times 30 ; 21,5^{\circ} /$ syn. $\mathrm{m}$. \\
\hline remainder of syn. $\mathrm{m}$. & $\begin{array}{r}335 ; 30^{\circ} \\
+20 ; 50^{\circ}\end{array}$ & $=0 ; 44,41$ syn. m. $\times 27 ; 58,8^{\circ} /$ syn. m. \\
\hline $\begin{array}{l}\text { ngitude at B2 } \\
5 \text { syn. m. }\end{array}$ & $\begin{array}{r}356 ; 20^{\circ} \\
+139 ; 50^{\circ}\end{array}$ & $\begin{array}{l}\left(=180 ; 20^{\circ} \text { past } \mathrm{B} 1\right) \\
=5 \times 27 ; 58,8^{\circ} / \mathrm{syn} . \mathrm{m}\end{array}$ \\
\hline progress to boundary & $\begin{array}{r}136 ; 11^{\circ} \\
+19 ; 19^{\circ} \\
\end{array}$ & $=0 ; 41,26$ syn. m. $\times 27 ; 58,8^{\circ} /$ syn. m. \\
\hline $\begin{array}{l}\text { remainder of syn. m. } \\
\text { ngitude at B3 }\end{array}$ & $\begin{array}{r}155 ; 30^{\circ} \\
+9 ; 23^{\circ} \\
164 ; 53^{\circ}\end{array}$ & $\begin{array}{l}=0 ; 18,34 \text { syn. m. } \times 30 ; 21,5^{\circ} / \text { syn. m. } \\
\left(=168 ; 33^{\circ} \text { past } \mathrm{B} 2\right) .\end{array}$ \\
\hline
\end{tabular}

$176 ; 0^{\circ}$

$+151 ; 45^{\circ}=5 \times 30 ; 21,5^{\circ} / \mathrm{syn} . \mathrm{m}$.

A conspicuous feature of both eclipse trios used by Hipparchus in the 
measurements of the radial ratio is that the first eclipse in each set fell near an equinox or solstice. This may have been an accident, but it was more likely the result of a deliberate decision to avoid the problem of computing solar daily motion over long intervals. In the (probably later) treatise "On the displacement of the solsticial and equinoctial points", as we have already seen, Hipparchus used observations of lunar eclipses to measure the longitudes of fixed stars in his own time and that of Timocharis (early third century), and not all these eclipses would have been close to solstices or equinoxes. ${ }^{49}$ We must assume therefore that by -127 Hipparchus had devised a way of estimating solar longitudes from the number of days since the vernal equinox. This might have been a simple conversion of the zone scheme, with the prescribed speeds divided by the number of days in one mean synodic month; but we have no proof of this.

The testimony of Vettius Valens still has to be taken into account. Were the solar tables that he mentions an authentic work of Hipparchus? Again, we simply do not know. It is doubtful whether the production of astronomical tables was one of Hipparchus's main goals in his astronomical researches. He possessed no planetary theory; and his lunar theory was marred by his inconsistent values for the radial ratio and his ignorance of the second anomaly. ${ }^{50}$ Hence it is not surprising that there is no ancient evidence for either lunar or planetary tables by Hipparchus. ${ }^{51}$ If he did publish solar tables, they were probably from his last years, and as likely as not their structure will have been closer to the Babylonian schemes than to Ptolemy's tables.

I began this article by comparing Ptolemy's deduction of the solar theory in Almagest III with Hipparchus's contributions to the subject. Ptolemy's explicit acknowledgements of his dependence on Hipparchus have encouraged modern readers to infer that the whole of Almagest III was hardly more than a rewriting of Hipparchus's lost works. It should now be clear that large parts of Ptolemy's treatment (including the computation of the tables of solar mean motion and anomaly in chapters 1-2 and 5-6, the determination of an epoch position in 7, and the discussion of the equation of time in 9) had no Hipparchian counterpart. Hipparchus turns out to have approached the theories of the Sun and Moon as a collection of separable problems to be solved as opportunity arose. He had no plan of systematically developing his theories independently of the existing Babylonian methods, for all that these methods were inconsistent with Hipparchus's geometrical models. Ptolemy's organization of the theories of the Sun, Moon, and planets into an apparently rigorous logical progress from which every trace of Babylonian methodology was ruthlessly expunged, must be seen as a radical reform of the science.

\section{Acknowledgements}

I am grateful to A. C. Bowen, J. P. Britton, B. R. Goldstein, and C. E. Haines for their comments to a draft of this article. The research has been carried out at the University of Toronto under a Canada Research Fellowship of the Social Sciences and Humanities Research Council of Canada. 


\section{BIBLIOGRAPHY}

Bernsen [1969] L. Bernsen, "On the construction of Column B in System A of the astronomical cuneiform texts", Centaurus, xiv (1969), 23-28.

Bowen-Goldstein [1988] A. C. Bowen and B. R. Goldstein, "Meton of Athens and astronomy in the late fifth century B.c.", in A scientific humanist: Studies in memory of Abraham Sachs, ed. by E. Leichty, M. de J. Ellis, and P. Gerardi (Philadelphia, 1988), 39-81.

Britton [in press] J. Britton, The quality of Ptolemy's solar and lunar observations and parameters (New York and London, in press).

Heiberg (See Ptolemy.)

Hipparchus (Manitius) Hipparchi in Arati et Eudoxi Phenomena Commentarium, ed. by K. Manitius (Leipzig, 1894).

Jones [1983] A. Jones, "The development and transmission of 248 day schemes for lunar motion in ancient astronomy", Archive for history of exact sciences, xxix (1983), 1-36.

Kugler [1900] F. X. Kugler, Die Babylonische Mondrechnung (Freiburg im Breisgau, 1900).

Neugebauer [1955] O. Neugebauer, Astronomical cuneiform texts (3 vols, London, 1955).

Neugebauer [1975] O. Neugebauer, A history of ancient mathematical astronomy (New York, etc., 1975).

Neugebauer [1988] O. Neugebauer, "A Babylonian lunar ephemeris from Roman Egypt", in $A$ scientific humanist ... (see Bowen-Goldstein [1988]), 301-4.

Pappus Pappi Alexandrini Collectionis quae supersunt, ed. by F. Hultsch (3 vols, Berlin, 1876-78).

Pingree [1978] D. Pingree, "History of mathematical astronomy in India", Dictionary of scientific biography, xv (New York, 1978), 533-633.

Ptolemy (Heiberg) J. L. Heiberg (ed.), Claudii Ptolemaei Opera quae exstant omnia, i: Syntaxis mathematica (2 parts, Leipzig, 1898-1903).

Ptolemy (Toomer) G. J. Toomer (transl.), Ptolemy's Almagest (London/New York etc., 1984).

Rome [1950] A. Rome, "The calculation of an eclipse of the Sun according to Theon of Alexandria", Proceedings of the International Congress of Mathematicians, Cambridge, Mass., U.S.A., Aug. 30-Sept. 6, 1950, i, 209-19.

Swerdlow [1980] N. M. Swerdlow, "Hipparchus's determination of the length of the tropical year and the rate of precession", Archive for history of exact sciences, xxi (1980), 291-309.

Tannery [1893] P. Tannery, Recherches sur l'histoire de l'astronomie ancienne (Paris, 1893).

Theon (Dupuis) Theon de Smyrne, philosophe platonicien: Exposition des connaissances mathématiques utiles pour la lecture de Platon, ed. \& transl. by J. Dupuis (Paris, 1892).

Theon (Hiller) Theonis Smyrnaei philosophi platonici expositio rerum mathematicarum ad legendum Platonem utilium, ed. by E. Hiller (Leipzig, 1878).

Toomer (See also Ptolemy.)

Toomer [1967] G. J. Toomer, "The size of the lunar epicycle according to Hipparchus", Centaurus, xii (1967), 145-50.

Toomer [1973] G. J. Toomer, "The chord table of Hipparchus and the early history of Greek trigonometry", Centaurus, xviii (1973), 6-28.

Toomer [1974] G. J. Toomer, "Hipparchus on the distances of the Sun and Moon", Archive for history of exact sciences, xiv (1974), 126-42.

Toomer [1978] G. J. Toomer, "Hipparchus", Dictionary of scientific biography, xv (New York, 1978), 207-24.

Toomer [1988] G. J. Toomer, "Hipparchus and Babylonian astronomy", A scientific humanist ... (see Bowen-Goldstein [1988]), 353-62.

Van der Waerden [1988] B. L. van der Waerden, Die Astronomie der Griechen (Darmstadt, 1988).

Vettius Valens (Kroll) Vettii Valentis Anthologiarum libri, ed. by W. Kroll (Berlin, 1908).

Vettius Valens (Pingree) Vettii Valentis Antiocheni Anthologiarum libri novem, ed. by D. Pingree (L6ipzig, 1986).

\section{REFERENCES}

I. Almagest I, 2 (Toomer, 37; Heiberg I, 8-9) and III, Preface (Toomer, 131; Heiberg I, 191).

2. Almagest III, 1 (Toomer, 139; Heiberg I, 206-8).

3. According to Theon of Smyrna (Dupuis, 256-7; Hiller, 127), this was Hipparchus's "On the sizes and distances"; but it is difficult to see how the determination of the solar model's 
parameters would fit in with the known contents of that work (for which see Toomer [1974]).

4. Almagest III, 4 (Toomer, 153; Heiberg I, 232-3).

5. See for example Neugebauer [1975], 306-7, 313, and Toomer [1978], 211. Rome [1950], 214-15, went so far as to maintain that even the exact format of the Almagest tables went back to Hipparchus.

6. Vettius Valens IX, 12 (Pingree, 339; Kroll, 354).

7. For the chronology of Hipparchus's discovery of precession, see Toomer [1978], 217-18, and Swerdlow [1980].

8. Almagest III, 1 (Toomer, 136; Heiberg I, 200-1).

9. Almagest III, 5 (Toomer, 165; Heiberg I, 251), and see also III, I (Toomer, 140; Heiberg I, 208).

10. Almagest III, 1 (Toomer, 135-6; Heiberg, I, 198-200) and VII, 2 (Toomer, 327; Heiberg II, 12-13).

11. Almagest III, 1 (Toomer, 135; Heiberg I, 199). All passages of the Almagest quoted in this article are from Toomer's translation.

12. Almagest III, 1 (Toomer, 136; Heiberg I, 200).

13. Almagest V, 3 (Toomer, 224; Heiberg I, 363-4) and V, 5 (Toomer, 227-8 and 230; Heiberg I, 369 and $374-5)$.

14. For how this could be done if one were using an armillary sphere, see Toomer's note 4 to Almagest V, 1 (p. 219).

15. Theon of Smyrna (Dupuis, 268 9 and 298-9; Hiller, 166 and 185). Tannery's claim ([1893], 60, since revived by van der Waerden (e.g. [1988], 180-1), that Hipparchus did not understand the easy geometrical proof of this equivalence derives from a mistranslation of the former passage of Theon.

16. Almagest IV, 5 (Toomer, 181; Heiberg I, 294-5).

17. Almagest IV, 11 (Toomer, 211-15; Heiberg, I, 340-7).

18. Ptolemy 'rounds' this to $133^{\mathrm{h}}$.

19. The possibility of errors in the textual transmission of the figures can be ruled out. The numerical consistency of Ptolemy's discussion of Hipparchus's intervals guarantees that we are reading exactly the same numbers that Ptolemy read in Hipparchus's book; while the fact that the intervals ascribed to Hipparchus lead (approximately) to Hipparchus's attested values for the ratio of radii assures us that these really were Hipparchus's numbers (cf. Toomer's note 75 to Almagest IV, 11 (p. 21f)).

20. For example, Toomer [1973], 26, note 10 writes: "One might, with difficulty, explain Hipparchus's errors in the time-intervals by supposing that he neglected or miscalculated the equation of time, but his errors in the longitude intervals are completely inexplicable to me." To my knowledge only Britton [in press] (chap. 2, "Ptolemy's solar tables") has said outright that the discrepancies imply a systematic difference between the ways that Hipparchus and Ptolemy computed solar longitudes.

21. There is a particular difficulty in the case of eclipse A3, where Ptolemy interprets a phrase that seems unambiguously to mean "Four hours past sunset" as if it meant "during the fourth hour", and therefore counts it as $3 \frac{1}{2}$ hours. I am inclined to attribute the inconsistency to a textual corruption (Toomer's note 68 to Almagest IV, 11 (p. 213)).

22. The fundamental theorems of spherical trigonometry are supposed to have first appeared in Menelaus's Spherics about A.D. 100. Pappus of Alexandria (Collection 6.109) informs us that Hipparchus used arithmetical functions for oblique ascensions.

23. For a detailed discussion of the equation of time, see Neugebauer [1975], 61-68.

24. 4 equinoctial hours is approximately the maximum duration of a lunar eclipse ( $c f$. Toomer's note 30 to Almagest IV, 6 (p. 191)). A duration of $3_{\frac{1}{2}}^{\text {th }}$ could follow from Hipparchus's measurement of the Earth's shadow as $2 \frac{1}{2}$ times the Moon's disk, combined with the crude assumption that the Moon travels the breadth of its own disk in about $I^{\mathrm{h}}$ with respect to the shadow.

25. I do not know of any direct evidence of knowledge of the equation of time before Ptolemy (cf. Neugebauer [1975], 61). In Indian astronomy, a partial correction for the inequality of days due to solar anomaly appears first in the seventh century in the astronomy of Brahmagupta (Pingree [1978], 569; cf. also 582).

26. Based on the difference between the maximum and mean solar motion per synodic month in Column A (see Neugebauer [1955], i, 70-71). The equations implicit in the System B solar scheme are actually about two-thirds of what they should be.

27. Neugebauer [1955], i, 4546 . 
28. Bernsen [1969].

29. Almagest IV, 11 (Toomer, 211; Heiberg I, 338-9).

30. The argument still holds if (as I am unable to believe) Hipparchus did not know that the hypotheses were geometrically equivalent ( $c f$. ref. 15 above).

31. Toomer [1967]. Ptolemy's account excludes the possibility that the measurement according to the epicyclic model preceded the measurement according to the eccentric model.

32. Although $f$ and $s$ vary in their seconds place depending on the choice of initial longitude $\lambda_{1}$, the year length resulting from them does not vary by more than 1 second for $175^{\circ} \leqslant \lambda_{1} \leqslant 177^{\circ}$.

33. Almagest V, 3 (Toomer, 224; Heiberg I, 363-4).

34. Almagest V, 5 (Toomer, 227; Heiberg I, 369).

35. Almagest V, 5 (Toomer, 230; Heiberg I, 374-5).

36. Almagest III, 1 (Toomer, 134; Heiberg I, 196).

37. Toomer [1978], 219 has already suggested that at least the longitude for -126 July 7 was observed.

38. Kugler [1900], 111. For a survey of how much Hipparchus knew of Babylonian astronomy in general, see Toomer [1988].

39. Neugebauer [1988].

40. Hipparchus I, 9 (Manitius, 88-90).

41. Bowen-Goldstein [1988], 68-69. Kugler [1900], 84-86 had already pointed out that Hipparchus's values for the lengths of both astronomical spring and astronomical summer are strikingly close to the values implied by System $\mathrm{A}$.

42. The two passages that seem to speak of solstice observations (III, 1; Toomer, 133 and 139; Heiberg I, 194-5 and 206-7) can be interpreted as referring to solstices calculated from observed equinoxes.

43. Almagest III, 1 (Toomer, 133 4; Heiberg I, 195 6).

44. Almagest III, 4 (Toomer, 153; Heiberg I, 233).

45. An interval of $90 \frac{1}{8}$ days for astronomical winter is a 'fringe benefit' of the determination of the solar model's parameters; and this value is expressly attributed to Hipparchus by Ptolemy (III, 4; Toomer, 155-6; Heiberg I, 237-8).

46. Almagest IV, 11 (Toomer, 211; Heiberg I, 338). See Toomer [1973] for a hypothetical reconstruction of Hipparchus's calculation of this ratio.

47. In fact the ratio that Hipparchus extracted from his first eclipse trio was significantly different from the exact ratio that one can recompute from his data (e.g. Toomer [1973], 12-15 recomputes 338:3134).

48. Hipparchus's confirmation of the period of latitude used his observation of the eclipse of -140 January 27 (Almagest VI, 9; Toomer, 309; Heiberg I, 526). Toomer [1978] has identified the Hipparchian eclipses used for the confirmation of the anomalistic period (cf. Almagest IV, 2; Toomer, 178; Heiberg I, 276) as those of - I40 January 27 (again) and -138 November 26.

49. E.g. the eclipse of -145 April 21, referred to in Almagest III, 1 (Toomer, 135 and note 14; Heiberg I, 199).

50. For Hipparchus on the planets, see Almagest IX, 2 (Toomer, 421; Heiberg II, 210). It is customary to interpret the observations of lunar elongations in $-127 / 126$ as evidence that Hipparchus suspected that his lunar model did not predict accurate longitudes away from syzygies; but of course without an accurate epicycle radius, it would not have worked well at the syzygies either.

51. Hipparchus's report of his observation on -127 August 5 of the lunar elongation provides a clue to what kind of lunar table he used at this late date in his career, and it was a Babylonian one. See Jones [1983], 25-26. 